\title{
CINE Y TEORÍAS CRIMINOLÓGICAS
}

\author{
NORBERTO HERNÁNDEZ JIMÉNEZ ${ }^{1}$
}

\section{RESUMEN}

El presente artículo pretende demostrar cómo a través del cine se pueden analizar tanto categorías dogmáticas del derecho penal, como teorías criminológicas. Estos temas, que en ocasiones se tornan difíciles de abordar con los estudiantes y el público en general, pueden simplificarse a través del uso de esta herramienta audiovisual, obteniendo mayor receptividad y construcción compartida de conocimiento.

Palabras ClaVe: Cine, criminología, derecho penal.

1 Asesor docente Grupo de Prisiones Universidad de los Andes e Investigador visitante de la Universitat Pompeu Fabra (Barcelona). 


\begin{abstract}
This paper aims to show how both (i) dogmatic categories of criminal law and (ii) criminological theories can be analyzed through movies. These two issues, which sometimes become difficult for students and the general public, can be simplified with the use of this audiovisual tool. In fact, movies help obtain greater academic openness and discussion.
\end{abstract}

KEY WORDS: Movies, criminology, criminal law. 


\section{INTRODUCCIÓN}

La criminología se convirtió en una disciplina de encuentro (Downes, citado por Rock y Holdaway, 1988, “Thinking About Criminology: <Facts are Bits of Biography>" p. 3), cuya competencia corresponde a varios saberes y profesiones (GARLAND, 2007, "La cultura de las sociedades con altas tasas de criminalidad. Algunas precondiciones de las políticas de seguridad ciudadana" p. 94; Matthews, 2003, Pagando tiempo. Una introducción a la sociología del encarcelamiento p. 307) $)^{2}$. El cine, por su parte, permite mostrar representaciones de la vida cotidiana y en materia delictiva, ofrece al espectador algunos detalles sobre el comportamiento criminal que pueden ser analizadas a través de las teorías criminológicas y el derecho penal $^{3}$, ante lo cual los textos de criminología, así como los distintos manuales de derecho penal, en ocasiones resultan densos para graficar estas situaciones.

Estudiar criminología a través del cine continúa siendo atractivo y novedoso ${ }^{4}$ y el tema en el ámbito colombiano ha sido relegado a un segundo plano. Sin embargo, el presente artículo pretende mostrar los beneficios del estudio del crimen y las reacciones

Incluso puede hablarse de "identidades criminológicas", siendo los franceses más cercanos a la sociología, los británicos a la medicina y los italianos a la antropología (LARRAURI, 2015 p. 24)

3 "El lenguaje cinematográfico está asociado casi desde el comienzo con el mundo del Derecho, aunque la afirmación pueda parecer paradójica" De Lucas (2003, Blade Runner: el Derecho, guardián de la diferencia p. 19)

4 Cfr. Atherton (2013); DeMERATH (1981); LiVINGSTON (2004) y RAFTER y BROWN (2011). DE LuCAS (2003), por su parte, ofrece un análisis de la inmigración - fenómeno estudiado por la criminología a partir de las teorías ecológicas de la desorganización social y la asociación diferencial-, a partir de la película Blade Runner. 
frente a éste dentro de un contexto cultural, por medio del análisis de películas que desde diversos ángulos y estilos, abordan esta temática, particularmente la construcción social y cultural del fenómeno criminal y su control, lo cual es correlacionado con el contexto colombiano.

Se pretende así, ofrecer una herramienta pedagógica en la enseñanza de estas disciplinas, que morigere los aspectos técnicos propios del derecho penal y la criminología, facilitando su entendimiento, no solo para los estudiantes de derecho y criminología $^{5}$, sino en general, para cualquier sujeto ajeno al conocimiento jurídico, que ante la propagación del crimen en todos los ámbitos de la vida cotidiana, puede encontrarse motivado frente al tema.

Para este efecto se ha dividido el texto en ocho temas, que se consideran fundamentales en el estudio de la criminología, los cuales serán contextualizados a partir de una o dos películas de manera principal y otros films que serán abordados de manera secundaria. En la escogencia de las películas se procuró omitir el estereotipo de Hollywood - lo que no se logró en todos los casos -, ofreciendo películas clásicas, permitiendo así una reflexión libre de prejuicios o la eventual desmotivación frente a historias ya observadas.

A continuación se relacionan las películas con base en las cuales se estudió cada uno de los temas propuestos y frente a las cuales se brindará un breve análisis en este texto:

5 “(...) en algunas ocasiones, los estudiantes se quejan de que hay muchas teorías criminológicas en los estudios de criminología y a ellos les gusta un conocimiento más práctico, más aplicado" (LARRAURI, 2015, p. 66) 


\section{CUADRO 1}

\section{Películas estudiadas}

\begin{tabular}{|c|c|c|}
\hline TEMA & PELICULAS & $\begin{array}{l}\text { OTRAS PELÍCULAS } \\
\text { SOBRE EL TEMA }\end{array}$ \\
\hline $\begin{array}{l}\text { Explicaciones biológicas } \\
\text { y psicológicas sobre el } \\
\text { crimen. }\end{array}$ & $\begin{array}{l}\text { M (Alemania, 1931, } 110 \\
\text { min.). Director: Fritz Lang } \\
\text { y Psicosis (EE.UU., 1960, } \\
109 \text { min.). Director: Alfred } \\
\text { Hitchcock. }\end{array}$ & $\begin{array}{l}\text { El silencio de los inocentes; } \\
\text { Monster; American Psycho }\end{array}$ \\
\hline $\begin{array}{l}\text { Explicaciones sociológicas: } \\
\text { anomia y tensión. }\end{array}$ & $\begin{array}{l}\text { Mean Streets (EE.UU., } \\
\text { 1973,112 min.). Director: } \\
\text { Martin Scorsese }\end{array}$ & $\begin{array}{l}\text { El Padrino (partes } 1,2 \\
\text { y 3); Goodfellas; Once } \\
\text { Upon a Time in America; } \\
\text { María llena eres de gracia; } \\
\text { Trainspotting; Scarface. }\end{array}$ \\
\hline $\begin{array}{l}\text { Explicaciones sociológicas: } \\
\text { exclusión y alienación en } \\
\text { la modernidad tardía. }\end{array}$ & $\begin{array}{l}\text { Taxi Driver (EE.UU., 1976, } \\
113 \text { min.). Director: Martin } \\
\text { Scorsese. }\end{array}$ & $\begin{array}{l}\text { Mean Streets; Satanás; } \\
\text { Asesinos por Naturaleza; } \\
\text { Boys don’t Cry }\end{array}$ \\
\hline $\begin{array}{l}\text { La escogencia racional del } \\
\text { crimen. }\end{array}$ & $\begin{array}{l}\text { Double Indemnity (EE. } \\
\text { UU., 1944, } 107 \text { min.). } \\
\text { Director: Billy Wilder }\end{array}$ & $\begin{array}{l}\text { El halcón maltés; The Big } \\
\text { Sleep; Sunset Boulevard; } \\
\text { Touch of Evil; The Third } \\
\text { Man; The Lady from } \\
\text { Shangai. }\end{array}$ \\
\hline $\begin{array}{l}\text { El espacio urbano y la } \\
\text { desorganización social } \\
\text { como factores generadores } \\
\text { del crimen. }\end{array}$ & $\begin{array}{l}\text { La Haine (Francia, 1995, } \\
98 \text { min.). Director: Mathieu } \\
\text { Kassovitz y Un profeta } \\
\text { (Francia, 2009, } 155 \text { min.). } \\
\text { Director: Jacques Audiard. }\end{array}$ & $\begin{array}{l}\text { La Sierra, Rodrigo D No } \\
\text { futuro, La vendedora de } \\
\text { rosas, Ciudad de Dios, Los } \\
\text { olvidados, Goodfellas, Mean } \\
\text { Streets, The Departed. }\end{array}$ \\
\hline $\begin{array}{l}\text { Las teorías del } \\
\text { etiquetamiento y el pánico } \\
\text { moral. }\end{array}$ & $\begin{array}{l}\text { The Thin Blue Line (EE. } \\
\text { UU., 1988, } 103 \text { min.). } \\
\text { Director: Errol Morris } \\
\text { (Documental) }\end{array}$ & $\begin{array}{l}\text { Capturing the Friedmans, } \\
\text { Summer of SAM. }\end{array}$ \\
\hline Crimen y control social. & $\begin{array}{l}\text { Los } 400 \text { golpes (Francia, } \\
\text { 1959, } 99 \text { min.). Director: } \\
\text { François Truffaut. }\end{array}$ & $\begin{array}{l}\text { A Clockwork Orange; Fight } \\
\text { Club; Reservoir Dogs; } \\
\text { Ciudad de Dios, Lord of } \\
\text { the Flies. }\end{array}$ \\
\hline $\begin{array}{l}\text { La criminología crítica y } \\
\text { la legitimidad del poder de } \\
\text { castigar. }\end{array}$ & $\begin{array}{l}\text { La batalla de Argel (Italia- } \\
\text { Argelia, 1966, } 121 \text { min.). } \\
\text { Director: Gillo Pontecorvo. }\end{array}$ & \\
\hline
\end{tabular}

Fte. Elaboración propia 
Para finalizar esta introducción, es importante resaltar la preocupación de los docentes en obtener receptividad por parte de sus estudiantes en los temas abordados en clase y, ciertamente la enseñanza del derecho penal y la criminología se ha camuflado recientemente bajo cierto misticismo, del cual somos responsables en gran medida los profesores y quienes escribimos sobre el tema. Insisto, este texto pretende desmitificar la enseñanza de estas disciplinas, acudiendo a una herramienta llamativa para el estudiante-espectador, que motiva su reacción y la construcción de conocimiento conjunto, acercándolo a la realidad, más allá del aprendizaje memorístico sobre las teorías dogmáticas que rodean el objeto de estudio.

\section{EXPLICACIONES BIOLÓGICAS Y PSICOLÓGICAS SOBRE EL CRIMEN ${ }^{6}$}

Cuando observamos el comportamiento criminal de Aileen Wuornos (Película Monster, 2003)7, Buffalo Bill (Película The silence of the lambs, 1991) ${ }^{8}$, Patrick Bateman (Película

6 "Para Lombroso, los sujetos delincuentes se diferencian del resto de los ciudadanos, y por influencia de DARWIN afirma que no han evolucionado al mismo ritmo que el resto de la humanidad y que, por tanto, exhiben rasgos de atavismo. Los delincuentes poseen características biológicas distintas, como la enfermedad mental, carecer de un sentimiento moral y el alcoholismo, que les determina a cometer delitos" (LARRAURI, 2015, p. 52). Sobre el tema ver AKERS y SELLERS (2009, Criminological Theories. Introduction, evaluation and application pp. 47-70), BARATTA (1989, pp. 31-34), CiD y LARRAURI (2001, pp. 57-77), DELISI (2012, “Revisiting Lombroso” pp. 5-21), HaGAN (2008, Introduction to Criminology. Theories, methods and criminal behavior pp. 117-144), LILLY, et. al (2007, Criminological theory. Context and consequences pp. 17-32), NEWBURN (2013, pp. 131-168) y SERRANO (2009, Introducción a la criminología pp. 243-282). http:/ / www.youtube.com/watch?v=vq70brIQP40.

http:/ / www.youtube.com/watch?v=1QKs169S10I. Ver también Rafter, 2006, p. 71 
American Psycho, 2000) ${ }^{9}$ y la representación de Peter Kurten, llevada a la pantalla grande por Fritz Lang (Película M, 1931), muy probablemente surjan muchas preguntas relacionadas con el estudio del criminal ${ }^{10}$, como: (i) el ¿por qué de esas conductas desviadas? y (ii) ¿cuál es la mejor estrategia de control social?

A continuación se abordarán algunas posibles respuestas a estos cuestionamientos desde una perspectiva criminológica, directamente vinculada a la imputabilidad penal. La criminología ha explorado varias teorías, que arrojarían como consecuencia de estos actos, desde la pena de muerte con base en una visión de proporcionalidad inspirada en la escuela clásica [criminología administrativa y legal (TAYLOR, et. al., 2007, La nueva criminología. Contribución a una teoría social de la conducta desviada p.23)], hasta el internamiento en un centro psiquiátrico como medida de rehabilitación promovida por FERRI, GAROFALO y Lombroso, dentro de la escuela positivista (pp.28 y s.s.).

Ahora bien, estos personajes pueden ser catalogados dentro de lo que la psiquiatría forense rotula como "psicópatas", siendo una de sus características, la completa ausencia de empatía que conduce a la realización de comportamientos socialmente desvalorados, con ausencia de frenos inhibitorios (CANCIO, 2013, Psicopatía y derecho penal: algunas consideraciones introductorias p. 533), satisfaciendo sus intereses netamente egoístas (TAYLOR, et. al., 2007 p.20).

9 http:// www.youtube.com/watch?v=XKEX1aaf1DI. Ver también RAFTER, 2006, p. 69

10 La criminología - como ciencia de la criminalidad- es ante todo, en sus orígenes, conocimiento del criminal (Meloss y PAVARINI, 1987, Cárcel y fábrica. Los orígenes del sistema penitenciario (Siglos XVI-XIX) p. 192). 
Para responder el primer cuestionamiento, relacionado con el ¿por qué de esa conducta?, la doctrina alemana (ANDERSON y KIEHL, 2012, "The psychopath magnetized: insights from brain imaging" p. 53)11 relaciona dos factores principales:

\begin{tabular}{|l|l|}
\hline \multicolumn{1}{|c|}{ GRÁFICO 1 } \\
\hline \multicolumn{1}{|c|}{ Factores principales que explican la conducta delictiva } \\
\hline $\begin{array}{l}\text { Elementos presentes } \\
\text { desde el nacimiento }\end{array}$ \\
$\begin{array}{l}\text { Influencias derivadas de la } \\
\text { historia vital del individuo }\end{array}$ & \multicolumn{1}{l}{ psópatas primarios } \\
\hline
\end{tabular}

Aunque en principio esta clase de personas no serían aptas para el castigo penal, desde la arista del libre albedrío y la autodeterminación (MoRse, 2008, "Psycopathy and criminal responsability" pp. 205 y 211 y TAYLOR, et. al., 2007 p. 248), la dogmática jurídico penal actual y en especial, la Jurisprudencia del Tribunal Supremo Español (CANCIO, 2013 p. 537), consideran que deben ser condenadas sin ninguna clase de distinción ni atenuación [como si lo harían los neoclásicos (TAYLOR, et. al., 2007 pp. 26 y 27)], ya que comprenden perfectamente lo ilícito de su hecho y no presentan dificultades de control de la conducta, advirtiendo que los psicópatas son todo lo contrario a impulsivos [lo que se acopla al problema del nihilismo terapéutico (TAYLOR,

En sentido similar RAFTER (2006, p. 70). 
et.al., 2007, p.43) y a su vez va en contravía de la tesis positivista (p. 42)].

Retornando al caso de Peter Kurten, analicemos una de las confesiones que le hizo al psicólogo Karl Berg, cuando le preguntó sobre la conciencia de sus actos ${ }^{12}$ :

No tengo. Nunca sentí arrepentimiento en mi alma; nunca pensé que lo que hice estaba mal aunque la sociedad lo condenara. Mi sangre y la de mis víctimas estará en la cabeza de mis torturadores. Debe de haber un Ser Superior que creara la chispa de la vida. Ese Ser juzgará buenos mis actos puesto que vengué mi injusticia. Los castigos que sufrí destruyeron todos mis sentimientos de ser humano. Por eso no tuve piedad con mis víctimas.

En este contexto, el defensor de Kurten (en la película) sostiene una posición positivista en virtud de la cual el asesino carece de continencia moral y no puede ponerle freno a su necesidad incontrolable de matar niños. De ahí que sus acciones no son su responsabilidad. Por eso sostiene que el asesino necesita un tratamiento, una rehabilitación, y no un castigo ${ }^{13}$.

12 Disponible on line: http:/ / www.el-parnasillo.com/elvampirodedusseldorf. htm

En el mismo sentido Taylor, et. al. - siguiendo a la corriente positivista -, señala que un criminal es una persona anormal y enferma, que precisa de tratamiento (2007, p. 28). Desde esta perspectiva, expone Ferrajoli que: "las penas asumen el carácter de medidas técnicamente apropiadas para las diversas exigencias terapéuticas $u$ ortopédicas de la defensa social: medidas higiénico-preventivas, medidas terapéutico-represivas, medidas quirúrgicoeliminativas, según los tipos de delincuentes ocasionales, pasionales, habituales, dementes o natos, así como de los factores sociales, psicológicos 
Nótese que la película exalta los rasgos comportamentales del sujeto criminal. Los silbidos compulsivos que acompañan siempre al asesino son una muestra de ello. De modo similar, las características físicas del sujeto criminal, tales como la mirada errática, pero al mismo tiempo increpante y siempre alerta; o incluso su frente, ancha y prominente, que recuerda características eminentemente Lombrosianas que contribuyen a crear el arquetipo criminal (RAFTER, 2006, Shots in the mirror. Crime films and society p. 64).

Si tanto él, como Aileen Wuornos, Jame Gumb y Patrick Bateman pueden ser considerados dementes ${ }^{14}$, sus conductas desde la óptica penal pueden ser consideradas típicas -porque reúnen los elementos objetivos y subjetivos del tipo penal de homicidioe igualmente son antijurídicas porque lesionaron de manera efectiva el bien jurídico tutelado de la vida. Estas dos categorías, sin lugar a dudas, serán superadas con suficiencia por el juzgador, pero ¿cómo hará para establecer de manera efectiva la situación de demencia de este sujeto? ¿La decisión sobre la culpabilidad, en definitiva, corresponderá al juez o al médico forense? Estas situaciones no están reguladas en la ley y es el poder disciplinario (medicina) el que en definitiva adopta la decisión ${ }^{15}$, debiendo

o antropológicos del delito" (2009, Derecho y razón. Teoría del garantismo penal p. 267)

"Un hecho significativo: la manera en que la cuestión de la locura ha evolucionado en la práctica penal. Según el Código francés de 1810, no se planteaba hasta el final del artículo 64. Ahora bien, éste dice que no hay crimen ni delito, si el infractor se hallaba en estado demencia en el momento del acto" (FOUCAULT, 1976, Vigilar y castigar. Nacimiento de la prisión p. 27).

De antaño, así lo ha reconocido implícitamente la jurisprudencia colombiana: "Para que tal situación se presente, debe ser cabalmente comprobada mediante pericia médica, no siendo suficiente la simple afirmación de la existencia del trastorno, sino que su existencia debe emanar de pruebas 
el poder soberano ceder ante su presencia (HERNÁndez, 2014, "Poder soberano y poder disciplinario. La codificación desde una visión foucaultiana" p. 147). Por esta razón, no es tan desacertado pregonar que en esta clase de casos, las togas negras deben ceder ante las blancas batas ${ }^{16}$.

Para el caso colombiano, encontramos una cercanía entre Luis Alfredo Garavito y Peter Kurten, quien si hubiera sido declarado inimputable -a pesar de la concepción social errada de impunidad-, podría haber sido condenado a una medida de seguridad $^{17}$, aparejada a un tratamiento médico por un largo tiempo.

Por otra parte, la obra Psycho (Robert Bloch, 1959), llevada a la pantalla grande por Alfred Hitchcock $(1960)^{18}$ permite escudriñar en el comportamiento de Norman Bates ${ }^{19}$ y las muertes que este

atendibles de donde surjan datos o antecedentes verosímiles relativos a la personalidad del inimputable y a la manera como normalmente se exterioriza a través de su usual comportamiento". Colombia, Rama Judicial del Poder Público, Corte Suprema de Justicia - Sala de Casación Penal - providencia del 26 de junio de 1985, proceso 1985, magistrado ponente Velásquez (1985).

La competencia en esta clase de delitos queda radicada preferentemente en cabeza del médico, desplazando al Juez (AKERS, 1994, Criminological Theories. Introduction, evaluation and application p. 165).

“Se establece un sistema de doble vía, el de penas para las personas racionales y el de medidas de seguridad para las personas que no tienen capacidad de razonar o controlar su comportamiento (técnicamente llamadas inimputables)" (LARRAURI, 2015, p. 53). También se hace referencia a esta consecuencia jurídica en la página 169 del mismo texto.

http://www.youtube.com/watch?v=NG3-GlvKPcg

Representa la historia del asesino en serie de Wisconsin (Ed Gein - "El carnicero de plainfield"). "Aparentemente era un hombre inofensivo... pero su personalidad ocultaba un terrible psicópata que convirtió su granja en un matadero humano. Sus espeluznantes crímenes proporcionaron a Hitchcock las bases para su clásica película de terror Psicosis." Recuperado de internet: 
ocasionó ${ }^{20}$; sin embargo, en la primera parte de la película, también permite observar la teoría de la elección racional del delincuente (Marion Craine) al apoderarse de una suma importante de dinero (U\$40.000), aprovechando la confianza en ella depositada, lo cual realiza con el objetivo de tener una estabilidad económica para compartir con su pareja sentimental.

Ahora bien, la belleza de Marion Craine no resulta desprevenida, en la representación que hace Hitchcock, para el análisis de esta teoría. Las características físicas de aquella son las que propician el comportamiento homicida de Bates al sentirse atraído y al mismo tiempo confundido por el trastorno de personalidad, que hace aparecer a su progenitora (en su cabeza) quien rechaza esta atracción, terminando de esta manera actuando en contra de la vida de una persona bajo un edipo materno que se encontraba dentro de sí. Utilizando los términos de Freud podríamos decir que esa belleza está relacionada con el súper yo del delincuente (BARATTA, 1989, Criminología crítica y crítica del derecho penal p. 45), que lo enloquece y despierta en definitiva un comportamiento paranoide, mismo que le impide actuar libre y consciente frente a sus actos.

De la misma manera podríamos aventurarnos frente a una explicación de los otros dos homicidios mencionados al final de la película (relatados por su autor al psiquiatra) y cuyos cuerpos, muy probablemente se encontraban en el fondo del pantano, aledaño a la casa y donde escondía los cadáveres de sus víctimas. No ocurre lo mismo con el homicidio del investigador privado, cuya motivación es sustancialmente diferente, al pretender

http://www.escalofrio.com/n/Asesinos/Ed_Gein_-_El_carnicero_de_ Plainfield/Ed_Gein_-_El_carnicero_de_Plainfield.php 
eliminar los rastros del delito pero que guardan relación en la medida que es ese otro yo de Bates, el que realiza la conducta homicida.

De esta manera, las películas analizadas ofrecen suficientes insumos para determinar no solo la enfermedad de los delincuentes sino el origen de su patología y el tratamiento con base en el cual el derecho penal debe responder a esta clase de actitudes, en las cuales el libre albedrío pregonado por BECCARIA (LARRAURI, 2015, Introducción a la criminología y al sistema penal p. 50), se encuentra ausente.

\section{EXPLICACIONES SOCIOLÓGICAS SOBRE EL CRIMEN: ANOMIA Y TENSIÓN ${ }^{21}$.}

En su obra El contrato social, RousSEAu expresa que "El hombre nace bueno y la sociedad lo corrompe", lo que se traduce en que el hombre es producto del contexto social en el que se encuentra, iniciando por la familia y continuando con el entorno que lo rodea. En cuanto al primer grupo citado, que a voces del constituyente del año 1991 -para el caso colombiano- constituye el núcleo de la sociedad (artículo 42 Constitucional), encontramos que "la familia es, desde luego, la principal cadena de transmisión para

21 “Unas aspiraciones que el orden social universaliza, aumenta y transforma en valor económico, y un acceso desigual a los recursos legales que permiten satisfacerlas, conllevan a que la persona esté en disposición de recurrir a medios ilegales. La existencia de estos, junto con unos grupos que enseñan a utilizarlos y a neutralizar los vínculos morales, propiciará la comisión de actos delictivos" (LARRAURI, 2015, p. 70). Sobre el tema ver AGNE (1997, "The Nature and Determinants of Strain: Another Look at Durkheim and Merton" p. 23-51), AKERS y SELlers (2009, pp. 177-210), CID y LARRAURI (2001, pp. 125-150), HAGAN (2008, pp. 145-150), LILLY, et. al (2007, pp. 5378), NEWBURN (2013, pp. 169-186) y SERRANO (2009, pp. 339-388). 
la difusión de las normas culturales a las generaciones nuevas. Pero lo que pasó inadvertido hasta muy recientemente es que la familia transmite en gran parte aquella parte de la cultura que es accesible al estrato social y a los grupos en que se encuentran los padres" (MERTON, 1992, Teoría y estructuras sociales p. 237).

En este sentido resulta bastante gráfico el personaje de Michael Corleone (The Godfather - Mario Puzzo, llevado a la pantalla grande por Francis Ford Coppola y protagonizado por $\mathrm{Al}$ Pacino $^{22}$ ) quien luego de acabar su carrera militar y con ocasión del atentado contra la vida de su padre ${ }^{23}$, decide tomar venganza (vendetta $)^{24}$. Michael termina dirigiendo la familia Corleone y hereda el título de Padrino, con las implicaciones delictuales que esto conlleva.

En una situación similar, aunque no idéntica, se encuentra Charlie (Película Mean Streets, 1973) ${ }^{25}$ quien dentro del fenómeno de la migración italiana a los Estados Unidos, creció en un ambiente delictual que le generaba dilemas éticos sobre lo bueno y lo malo.

22 http://www.youtube.com/watch?v=gCVj1LeYnsc

23 La guerra de los Corleone con las otras familias (mafias) de New York se origina por la negativa de Don Vito para hacer parte del negocio del narcotráfico.

24 "La sociedad ya no castiga - si es que alguna vez lo hizo-, sino que delega su función en un aparato estatal y en instituciones especializadas al margen de la sociedad. Los actos emotivos de venganza se volvieron tabú hace mucho tiempo -por lo menos en la conducta oficial-, y fueron desplazados por lo que parecen ser procesos racionales de control de la delincuencia" (GARLAND, 1999, p. 44). Curiosamente en las dos películas analizadas, la venganza fue el medio de control social por excelencia, en contra de Johnny Boy y de los opositores de la familia Corleone, cobrando también la vida de algunos integrantes de esta última. Incluso en la primera escena del Padrino, Don Vito es requerido por Bonasera para vengarse, frente a un fallo judicial que consideraba injusto.

http:/ / www.youtube.com/watch?v=rCwjzn0CncA 
Charlie, a diferencia de Michael, aspiraba heredar los negocios de su tío (voluntariamente), mientras que Michael se vio obligado a hacerse cargo de la familia, a pesar de que su conciencia inicial no se compaginaba con estos ideales, terminando encuadrados ambos, en definitiva, bajo lo que MERTON rotula como "pecado socialmente inducido" (MERTON, 1992, p. 209).

Y aquí resulta interesante analizar la relación que existe entre las dos películas frente a la presión religiosa que cargan los protagonistas, lo cual se observa desde la primera escena en la que aparece Charlie, mientras que respecto de Michael solo se vislumbra al final de la saga. Esto por cuanto en últimas, el delito trasgrede el código moral impartido por la religión (pecado) dentro de una cultura teocrática, fuertemente arraigada en las costumbres de estos delincuentes ${ }^{26}$.

Analicemos ahora el entorno social del delincuente ${ }^{27}$. Tanto el padrino como mean streets se desarrollan en la pequeña Italia (Manhattan-New York). En la segunda de las películas citadas, Charlie y sus amigos se encuentran en medio de un ambiente criminal (RAFTER, 2006 p. 66) que los lleva a reproducir las conductas sociales que culturalmente los han acompañado a lo largo de su vida. Aquí es preciso también analizar como el paradigma de éxito dentro de una sociedad de consumo se ve

26 El delito es "una violación al código moral básico que la sociedad considera sagrado" (GARLAND, 1999, p. 46). Al respecto resultan interesantes las películas "La virgen de los sicarios" http://www.youtube.com/ watch?v=1O_QZV1ImFE o "rosario tijeras" http://www.youtube.com/ watch? $v=Y Q 91 n R 3 m w 78$ en donde a pesar de segar la vida de algunas personas, encomendaban su accionar criminal a la Virgen María e incluso rezaban las balas para que llegaran al blanco propuesto.

"environmental theories of crime" (RAFTER, 2006, p. 65) 
directamente relacionado a la capacidad adquisitiva de dinero y que las oportunidades de obtención del mismo se ven limitadas por la inequitativa distribución de la riqueza (MERTON, 1992 p. 223), que lleva a una solución ágil y rápida consistente en la obtención de recursos a través del delito -innovación (CID y LARRAURI, 2001, Teorías criminológicas p. 130), máxime cuando el ambiente en el que se desarrolla el individuo, así lo propicia.

Finalmente, la conducta de Jhonny Boy, termina vulnerando los parámetros de conducta establecidos dentro de la sociedad en la que habita (MERTON, 1992 p. 212) y cuyo castigo resulta directamente impartido por el rechazo social a su comportamiento ${ }^{28}$. Este ejemplo resulta de utilidad para examinar la teoría de la anomía de Durkheim (Merton, 1992 pp. 213 y 227). Jhonny es un individuo que se encuentra en imposibilidad de acceder a los medios que sirven para obtener los fines socialmente establecidos y por esto se vuelve un rebelde del sistema (Merton, $1992 \mathrm{p}$. 224), obviando incluso las reglas del subsistema criminal en el que se desenvuelve.

28 "Por ello el derecho penal se basa, por lo menos en parte, en una reacción emocional compartida causada por la profanación de la cosas sagradas" (GARLAND, 1999, p. 47). "Los delitos son ofensas en contra del orden moral sagrado de la sociedad, lo que a su vez corresponde a sentimientos profundos de cada uno de sus miembros. (...) El resultado es una reacción apasionada y hostil de parte del público, que exige el castigo para el infractor" (GARLAND, 1999, p. 48). Ver también DURKHEIM, 1998, La división del trabajo social pp. 79 y s.s. 


\section{EXPLICACIONES SOCIOLÓGICAS SOBRE EL CRIMEN: EXCLUSIÓN Y ALIENACIÓN EN LA MODERNIDAD TARDÍA ${ }^{29}$}

Son múltiples las lecturas criminológicas que se pueden hacer a través del film Taxi Driver ${ }^{30}$, protagonizado por Robert de Niro (Travis Bickle) y dirigido por Martin Scorsese. Retomando la escuela positivista podríamos adentrarnos en el análisis del comportamiento de Travis, despojándolo de su título de "héroe" y reemplazándolo por el de "enfermo", lo cual se podría explicar por sus traumas adquiridos en Vietnam, que ameritarían un tratamiento médico ${ }^{31}$. También podríamos analizar la anomía pregonada por DurKheIM y MERTon, dentro de un contexto social (ManhattanNew York) que conlleva al accionar delictivo con base en el entorno que rodea a sus protagonistas. Muy conectado con esta idea, este acápite se limitará a la teoría de la desorganización social de la Escuela de Chicago (RAFTER y BROWN, 2011, Criminology goes to the movies: Crime Theory and Popular culture pp. $67 \mathrm{y}$ s.s.) que radica el objeto fundamental para el análisis de las causas del delito en el lugar y no en la gente ${ }^{32}$.

En este sentido, Manhattan (escenario también de mean streets) puede ser reemplazado fácilmente por Ciudad Gótica ${ }^{33}$ o las

29 Sobre el tema ver CID y LARRAURI (2001, pp. 79-98), HAGAN (2008, pp. 153-174), LiLLY, et. al (2007, pp. 33-52), NEWBURN (2013, pp. 187-214) y SERRANO (2009, pp. 389-436).

http:/ / www.youtube.com/watch?v=44gB58YS53A

31 En este punto es importante anotar que incluso Betsy, considera que Travis puede ser un sicótico (RAFTER y BROWN, 2011, p. 76).

En determinadas áreas geográficas donde confluyen la pobreza, la movilidad de la población, la transitoriedad de las relaciones sociales y la presencia de inmigración, existen menos controles sociales que actúan como herramienta de contención frente a la comisión de delitos (LARRAURI, 2015, p. 67)

http://www.youtube.com/watch?v=m7dapUWHykw 
favelas de Rio de Janeiro ${ }^{34}$, obteniendo un ambiente propicio para el análisis de esta teoría, donde los actores deben ceder su papel protagónico, ante la preponderancia del lugar, en el argumento criminológico bajo análisis. En estos lugares reina la pobreza, la inmigración y la fluctuación de valores que conllevan a la comisión de delitos (RAFTER y BROwN, 2011 p. 67), haciendo de estas conductas algo normal (Young, 2003, La sociedad excluyente: exclusión social, delito y diferencia en la modernidad tardía p. 33), especialmente en los ghettos judíos, tugurios italianos, salones de baile y barrios emergentes localizados en determinadas partes de la ciudad ${ }^{35}$. Es decir, que el fenómeno no abarca toda la metrópoli, sino determinados sectores de ella, primordialmente ubicados en el centro de la misma, aunque en el caso de la ciudad de dios (2002), esta perspectiva se observe en la periferia ${ }^{36}$, ostentando en todo caso la connotación de "zona de transición" 37 dentro de los anillos concéntricos analizados por la Escuela de Chicago que constituyen un símbolo de la asimetría entre la exclusión económica y la social (Young, 2003, p. 46).

34 https:// www.youtube.com/watch?v=-mKWzJzycRE

35 "Sus áreas constituyen la morada de las madres solteras y los padres irreflexivos, mientras que sus economías se sostienen sobre las drogas, la prostitución y el tráfico de mercaderías sustraídas" (YounG, 2003, p. 42)

Un fenómeno similar se observa en Bogotá (Colombia) respecto de la localidad de Ciudad Bolívar, aun cuando en el centro de la ciudad podemos observar esta situación en el reconocido "cartucho" que posteriormente mutó hacia el "Bronx". También paradigmático el caso de Medellín con la Comuna 13. En este contexto expresa GARLAND (2007, p.237) que "en el curso de una sola generación, la criminalidad se convirtió en una parte prominente de la vida, no sólo de la clase media urbana, sino también de buena parte de la clase media de los suburbios"

La película comprende también dentro de estas zonas de transición al Bronx y Harlem, en la ciudad de New York. 
Ahora bien, en taxi driver podemos observar como Travis se encuentra inmerso en un contexto que podríamos catalogar como "podrido" desde su visión, propia de aquel que recorre las calles en las horas de la noche abordo de un taxi, donde puede observar la escoria de la sociedad. El inconformismo de Travis con el entorno que lo rodea es tan profundo, que incluso al conversar con el candidato presidencial (Palantine) -a quien transporta como pasajero y luego decide matar por móviles que no resultan muy claros, pero que se infiere se encuentran relacionados con Betsy y con la imposibilidad de que a través de la política se obtenga una solución satisfactoria a los males de la sociedad -, clama por la limpieza de la ciudad.

Ante este panorama sombrío, Travis decide actuar a favor de una menor dedicada a la prostitución, matando a su proxeneta y cómplices, logrando evadir el rotulo de "homicida" y adquiriendo el noble atributo de "héroe" (RAFTER, 2006 p. 189) ante su actuar osado en contra del crimen ${ }^{38}$. Este vigilante (vengador) que actúa en evidente violación de la ley (RAFTER, 2006 pp. 194 y 195) no es merecedor de un reproche, que podría traducirse en prisión e incluso en la pena de muerte -en algunos Estados Norteamericanos- sino de un aplauso y exaltación social por su lucha contra los males de la sociedad, según lo muestra la película.

38 "Las rutinas privadas defensivas son comunes y existe un extenso mercado en el área de la seguridad privada" (GARLAND, 2006, p. 258). Un ejemplo similar nos otorga YOUNG en los siguientes términos: "una muerte de una persona puede ser tomada como un acto de heroísmo si es causada por un oficial de policía que se enfrenta a los ladrones armados, pero puede considerarse un acto de extrema inmoralidad si ha sido provocada por los ladrones" (2003, p. 69). En el mismo sentido RAFTER (2006, p. 198). 
El dilema de esta clase de comportamientos radica al confrontarlos con la teoría del contrato social y la cesión que los asociados realizamos ante el Leviatán para la protección de nuestros derechos. Si cada quien se vuelve un justiciero y administra la justicia con sus propias manos, se debilita la democracia y se habilitan las arbitrariedades con tan nefastos resultados como las ejecuciones extrajudiciales o el surgimiento de grupos armados de autodefensas, para el caso colombiano.

\section{LA ESCOGENCIA RACIONAL DEL CRIMEN ${ }^{39}$}

Double indemnity ${ }^{40}$ nos separa de la disyuntiva clásica y positivista, paraubicarnos delleno en la visión de BECCARIA frente al individuo egoísta que actúa con libertad de autodeterminación (escuela clásica) ${ }^{41}$. Precisamente el filme, muestra la manera en que un sujeto criminal no necesariamente debe ser un enfermo o un ser anormal. Por el contrario, el protagonista (Walter Neff), es un trabajador promedio de una compañía de seguros que, tal como el norteamericano de a pie, tiene en su mente la idea del

39 Sobre el tema ver AKERS y SELLERS (2009, pp. 17-46), BARATTA (1989, pp. 25-31), Cid y LARrauri (2001, pp. 33-56), Clarke y CORNISH (1985, Modeling Offenders. Decisions: A Framework for research and Policy pp. 150161), HAGAN (2008, pp. 99-104), LiLLY, et. al (2007, pp. 15-17 y 265-284), NEWBURN (2013, pp. 113-129) y SERRANO (2009, pp. 306-331).

40 http://www.youtube.com/watch?v=S3wjJcuGsVE

41 “La segunda idea proveniente de BECCARIA y que tiene, en nuestra opinión, importancia para el posterior desarrollo de las teorías criminológicas, es su imagen del hombre. Ciertamente, si el castigo es útil es porque el hombre está en capacidad de razonar, de comparar el beneficio del delito con el coste de la pena. En consecuencia, surge implícita la imagen de que todos los hombres tienen esa capacidad de raciocinio. Pero además se presume que el coste-beneficio será el determinante en la actuación humana" (CID y LARRAURI, 2001, p. 36) 
éxito idealizada a través del simbolismo del sueño americano, el cual incluye posesiones materiales y sentimentales. Debido a la influencia de Phylis Dietrichson, Walter se ve tentado hacia la idea de cometer un crimen en contra de un sujeto adinerado. El propósito: lograr venderle al sujeto una póliza de seguro cuyo valor está aumentado al doble. Posteriormente, se asesinaría al hombre, aparentando un accidente fatal que posibilitaría cobrar el valor del seguro. Esto llevaría a que el protagonista no solo obtuviera beneficios económicos sustanciales, sino a que también ganara el amor de la señora Dietrichson. En el desenlace, Walter comete el crimen, actuando siempre bajo la influencia de la señora Dietrichson, conocida en la teoría del cine negro como la femme fatale (RAFTER, 2006, p. 19) y utiliza sus conocimientos del funcionamiento interno de la agencia de seguros para intentar cobrar el monto del valor estipulado en la póliza.

La pregunta en este caso sería: ¿Qué tan racional resulta el homicidio de una persona para obtener una indemnización de una compañía de seguros, frente a la posibilidad de ser atrapado por las autoridades ${ }^{42}$ y condenado por un delito que le representará una larga estadía en un establecimiento penitenciario?

Previo a resolver este interrogante, consideramos pertinente anotar ciertos comentarios desde la perspectiva del análisis económico del derecho, que permitirán proveer de insumos la discusión. Los legisladores en materia penal, usualmente han considerado que al aumentar las penas se disminuye el índice de delitos.

42 En especial por Barton Keyes, dentro del caso concreto. 
Esa elección racional del delincuente ${ }^{43}$ corresponde a la siguiente fórmula:

La fórmula para decidir el monto de los daños si es menor que uno la probabilidad de que el delincuente sea efectivamente atrapado y obligado a pagar los daños es $\mathrm{D}=\mathrm{L} / \mathrm{p}$, donde $\mathrm{D}$ es el monto óptimo de los daños, $\mathrm{L}$ es el daño causado por el delincuente si es atrapado (incluido cualquier ajuste que se haga para desalentar la elusión del mercado que transfiere riqueza por medio de la coerción), y p es la probabilidad de ser atrapado y obligado a pagar los daños óptimos (PosNer, 2011, Análisis Económico del Derecho p. 213).

Similar teleología se aplica en la fase legislativa ${ }^{44}$ cuando, por ejemplo, se acude al dispositivo amplificador del tipo: tentativa y su consagración legal como punible, incrementando así los costos esperados por el infractor de la ley penal (PosNer, 2011 p. 224). Es por esta razón que, en un sistema judicial debilitado y con altos índices de impunidad -como el colombiano-, la existencia de la pena no cumple la función disuasoria esperada en contra del delincuente ${ }^{45}$, ya que éste cuenta con la probabilidad a su favor, de no resultar judicializado (HERNÁNDEZ, 2012, p. 81).

Sobre la elección racional del delincuente ver RUBIO (2007, Economía Jurídica. Introducción al análisis económico del derecho iberoamericano p. 317). Una crítica sobre este modelo consiste en que el delincuente no conoce todos los costos y beneficios del delito (AKERS, 1994, p. 58-60).

Lo que algunos autores denominan el “AED normativo”. Cfr. PINZÓN, 2010, Aproximaciones al análisis económico del derecho p. 56

$\mathrm{Al}$ respecto Von HIRSCH, et al., p. 1-3. Esta certeza está comprendida dentro de la regla de la certidumbre absoluta foucaultiana: “De ahí la idea de que el aparato de justicia debe ir unido a un órgano de vigilancia que le esté directamente coordinado, y que permita o bien impedir los delitos o bien, de haber sido conocidos, detener a sus autores" (FOUCAULT, 1976, p. 101). 
Al respecto manifestaba BECCARIA, inspirado en BENTHAM, en torno a criterios de prevención general negativa ${ }^{46}$ y la eficiencia en la función de administrar justicia, lo siguiente:

Lo que BECCARIA propone es una ecuación para determinar en qué momento una pena deja de cumplir su función. El valor esperado del delito es igual al "bien" perseguido por el delincuente, multiplicado por la probabilidad de que dicho "bien" se obtenga (o, lo que es lo mismo, el valor absoluto del "bien" perseguido menos la probabilidad de no obtenerse). Acto seguido debe tomarse el "mal" de la pena prevista y multiplicarse por la probabilidad de que la pena resulte impuesta (la infalibilidad de la pena). $\mathrm{Si}$ el valor resultante es mayor al primero, entonces la pena prevista consigue su objeto (NUÑEZ, 2000, Antecedentes y principios fundamentales del análisis económico de la ley p. 68)

La prevención general negativa pretende que la colectividad se abstenga de cometer delitos por el miedo de ser castigados con una pena; es una amenaza. Este criterio teleológico se compagina con la función simbólica del derecho penal: "La funcionalidad del derecho penal hace que éste no sólo se desenvuelva como instrumento con que cuenta el ciudadano para limitar el poder político en el ámbito del delito y de la pena y como ámbito de ejercicio del poder que, a través del castigo, se orienta a su legitimación por la sola razón de su ejercicio. Su multiplicidad funcional hace que también le sea inherente un desenvolvimiento como instrumento de construcción de la realidad social independientemente del incumplimiento de sus funciones declaradas, como un mecanismo capaz de influir en el imaginario social determinando creencias y conductas a partir de una sola razón de su positividad y sin vinculación alguna con las sanciones que siguen a los preceptos, como un elemento capaz de incidir en las representaciones de las personas y, en consecuencia, alentando por una pretensión de legitimidad desvinculada de sus evidentes limitaciones prácticas" Urbano, 2001, La legitimidad de derecho penal. Equilibrio entre fines, funciones y consecuencias p. 140 
La elección racional postulada por BECCARIA, en relación con la película en cuestión, tiene su sustento en dos consideraciones. En primer lugar, el protagonista no es un ser anormal ni un psicópata. Por el contrario, se trata de un sujeto que cualquier persona podría cruzarse en un andén en un día normal. En segundo lugar, el protagonista sopesa los beneficios y los costos antes de cometer el acto criminal. Él sabe que del lado X de la balanza está la posibilidad de obtener 100,000 dólares y el amor de la hermosa dama que siempre ha pretendido. Del otro lado de la balanza (Y), está la posibilidad de que su intento fracase, de ser juzgado por sus actos, y de quedarse -a fin de cuentas- sin el dinero y sin la mujer (RAFTER, 2006, p. 14). Esta segunda posibilidad se torna más sobrecogedora en la medida en que Keyes, un experimentado sabueso de los seguros, al parecer jamás se equivoca a la hora de distinguir entre la posibilidad de que el seguro sea cobrado sobre la base de un verdadero accidente, o si éste solamente se cobra con el fin de aparentar un accidente para beneficiar, ilegítimamente, al acreedor.

En el curso de la película vemos la manera en que, siguiendo postulados utilitaristas, los cuales están basados en la maximización del placer -y en los cuales descansa buena parte del sustento filosófico de la teoría de la acción racional-, el protagonista se inclina por la opción que le brinda la posibilidad de ganar los 100,000 dólares y la mujer deseada. Lo anterior obedece a la constante influencia de la femme fatale sobre el protagonista, siendo esto una característica fundamental de los filmes negros.

Pero, además de la influencia de esta mujer, lo anterior se debe a que el protagonista se percibe a sí mismo como un experto en el mundo de los seguros, capaz de burlar al sistema y de eludir la 
inteligencia del sabueso Keyes. Así pues, los beneficios, para el protagonista, superaron a los costos, lo cual derivó, tal como sería predecible desde la teoría de la acción racional, en la perpetración del crimen.

\section{EL ESPACIO URBANO Y LA DESORGANIZACIÓN SOCIAL COMO FACTORES GENERADORES DEL CRIMEN ${ }^{47}$}

Para abordar este tema resulta oportuno hacer mención conjuntamente a las películas La Haine ${ }^{48}(1995)$ y Un prophète ${ }^{49}$ (2009). Estos films permiten graficar la teoría de Sutherland (1939 Principios de Criminología y 1940 Delincuenciadecuelloblanco.) sobre la relación de los individuos con un medio delincuencial (ambiente de aprendizaje) que degenera en el desarrollo de estas capacidades frente al primero (en similar sentido a la teoría de la desorganización social pregonada por la Escuela de Chicago, con algunas variantes que serán expuestas más adelante), advirtiendo que esta correspondencia (medio delincuencial-delincuente), no opera per se al interior de estos contextos ${ }^{50}$, debiendo agregar en la ecuación un ingrediente adicional: los estímulos para obedecer la ley -asociación diferencial- ${ }^{51}$.

47 Sobre el tema ver AKERS y SELLERS (2009, p. 177), BARATTA (1989, pp. 6682), Cid y LARRAUri (2001, pp. 99-124), HAGAN (2008, pp. 155-156), LiLly, et. al (2007, pp. 41-52), NEWBURN (2013, pp. 187-214) y SERRANO (2009, pp. 389-436).

48 http://www.youtube.com/watch?v=yk77VrkxL88

49 http://www.youtube.com/watch?v=-MD7JA4BeOU

50 “(...) la simbiosis puede definirse como la costumbre de vivir juntos que presentan organismos de diferentes especies dentro del mismo hábitat" (TAYLOR, et. al., 2007, p. 137)

51 Lo contrario significaría una fórmula en el siguiente sentido: Medio delincuencial + individuo $=$ delincuente. La fórmula de SUTHERLAND 
En cierta medida, la tesis de Sutherland nos retrotrae al pensamiento de RoUSSEAU nuevamente, en cuanto a la bondad del individuo al nacer y su maleabilidad por parte de la sociedad, dentro de ese proceso de aprendizaje constante y la posibilidad de optar por dos caminos: el delito o la legalidad. Las preguntas que surgen, directamente vinculadas con las películas analizadas son: ¿Qué camino se debe tomar al interior de una cárcel cuando el medio delincuencial es más fuerte que la institucionalidad y la legalidad puede implicar, incluso, el compromiso de la vida misma? (Un prophète) y ¿Cómo actuar al interior de un barrio (proyecto) ${ }^{52}$ que vive en constante enfrentamiento con la Policía, rotulando esta fuerza pública a los integrantes de dicho territorio, como delincuentes? (La Haine). Para responder estas preguntas, debemos abordar el tópico de las subculturas ${ }^{53}$.

Muy a pesar del pensamiento lógico acerca de que en la Cárcel se restringen al máximo las actividades de los individuos, sometidos al control del Estado bajo la privación de la libertad,

estaría comprendida de mejor manera bajo los siguientes lineamientos: Medio delincuencial + individuo con estímulos mayores para cometer delito que para obedecer la ley = delincuente. "La teoría de la asociación diferencial sostiene que una persona se hace delincuente por un exceso de definiciones favorables a dicha violación. Sostiene también que estas definiciones se aprenden mediante un proceso de aprendizaje normal" (TAYLOR, et. al., 2007, p. 152). "La teoría de la asociación diferencial parte de que un colectivo desarrolla, en función de su ubicación en la estructura social, distintos valores, los cuales se transmiten de una persona a otra. Estos valores permiten la realización de delitos, ya sea porque no desvalorizan la comisión de (algunos) delitos, sea porque se neutraliza el daño implícito a (algunos) delitos" (LARRAURI, 2015, p. 69).

En este sentido, nuevamente hacemos referencia a las "zonas de transición" (TAYLOR, et. al., 2007, pp. 139, 140 y 150) adquirir prestigio) a un problema estructural (la falta de estatus debida a la escases de medios económicos)" (LARRAURI, 2015, p. 71) 
la realidad -visualizada en Un prophète con muy poca ficción - muestra que el manejo del poder se encuentra radicado en cabeza de determinados grupos que imponen sus reglas $\mathrm{y}$ coordinan el funcionamiento del establecimiento (GARCIAPablos de Molina, 1988, "Régimen abierto y ejecución penal" p. 41 y GARCÍA-BorÉS, 2003, "El impacto carcelario" p. 389). En este sentido la propuesta de la Escuela de Chicago resultaba insatisfactoria ya que la desorganización social, al interior de una Cárcel o en un territorio como el que muestra La Haine, tiene su propia organización, incluso jerárquica, con anomía (para recurrir a la teoría de Merton $)^{54}$ frente a los mandatos impuestos por otros sectores de la sociedad, pero, prevalidos de un sistema construido con base en sus propias cláusulas, dentro de un contrato social aplicable a los miembros de esta subcultura ${ }^{55}$.

Otra pregunta que surge inevitablemente en el análisis de estas cintas, tal y como se hacía en Taxi Driver, es: ¿Quién es el protagonista de estos films? Mientras que en Taxi Driver el protagonista era la ciudad, La Haine tiene un ámbito de análisis más restringido, que ya hemos anticipado: el Barrio (proyecto) y por supuesto en Un prophète será la Cárcel. En cuanto a los "proyectos" 56 y la relación que expone La Haine, paradigmática

54 En el mismo sentido TAYLOR, et. al., (2007, pp. 146 y 150)

55 En el mismo sentido BARATTA (1989, p. 195 y 197). "La ausencia de un sentido del deber entre los reclusos, la falacia de la coerción, la patética colección de recompensas o castigos para inducir la complicidad, las presiones para corromper al guardia disfrazadas de amistad, reciprocidad y transferencia de obligaciones institucionales a los reclusos de confianza, son más bien defectos estructurales del sistema de poder de la prisión que problemas individuales" (SYKES, 2007, The society of captives. A study of a maximum security prison p. 61).

56 En términos menos foráneos podríamos rotular estos sectores, para el ámbito colombiano, como lugares donde se construyen viviendas de interés social. 
resulta la escena en la galería que concluye con la expulsión del grupo de amigos integrado por un judío, un árabe y un afrodescendiente (lo cual no es accidental para el análisis de esta teoría) y la expresión del encargado del recinto sobre la "patología de los ghettos" que hace que estas personas, tengan un comportamiento diferente (anómico) al de los demás asistentes a la exhibición. Esta disyuntiva se representa también, en el mismo escenario, con base en la aproximación de estos sujetos a dos asistentes, del sexo opuesto, con quienes pretenden entablar una conversación, resultando frustrada su comunicación, por la diferencia de actitudes como consecuencia de la segregación social, enfatizada por la composición de este trío. En definitiva esto permite mostrar que los comportamientos desviados terminan siendo consecuencia del rechazo que perciben aquellos de la sociedad y que la rebeldía hacia esta los inspira a actuar asîn ${ }^{57}$.

La Cárcel y los proyectos nos permiten igualmente graficar la teoría de "las ventanas rotas" (WILSON, 1975, pp. 77-85), en cuanto, donde empieza un desorden social sin la adopción de medidas de control, preponderantemente a través de la intervención estatal (Policía-Guardias), se crea un escenario apto para la propagación del delito.

Congruente con lo anterior, el espectador de Un prophète fácilmente puede generar empatía con su protagonista y considerarlo una víctima del sistema. Así, cuando aquel intenta acudir a la institucionalidad frente a la coacción ejercida en su contra con miras a matar a otro recluso, so pena de morir, recibe una advertencia que le demuestra que quien dirige la Cárcel no

57

"Los adolescentes, enfrentados a la falta de normas, erigen su propia cultura al margen de los valores utilitaristas" (TAYLOR, et. al., 2007, p. 161) 
es el Estado, sino un grupo de internos con poder, que a su vez son los encargados de determinar la distribución de la riqueza al interior de este lugar. En igual medida en La Haine, el choque constante entre estos jóvenes y la fuerza pública, conlleva al resultado lamentable con que concluye la película: su muerte.

\section{TEORÍAS DEL ETIQUETAMIENTO Y EL PÁNICO MORAL ${ }^{58}$}

En el año 1976, el oficial de la policía Robert Wood fue asesinado, luego de descender de su patrulla y acercarse a un vehículo que transitaba con las luces apagadas. Al acercarse al conductor del rodante, fue impactado en varias oportunidades por disparos de arma de fuego, los cuales le ocasionaron la muerte. La policía de Dallas (Texas) carecía de pistas para dar con el paradero del conductor.

Luego de un buen tiempo, se pudo determinar la existencia de dos sospechosos, los cuales se relacionan a continuación: David Harris. Gracias a él se obtuvo la primera pista en la labor investigativa, ya que él comentó ante unos amigos que era el autor del homicidio perpetrado en contra del policía. Al localizarlo, proporcionó información sobre el paradero del arma homicida y el automotor en que se transportaban el día de los hechos, en

58 “(...) la delincuencia tiene que ver con los procesos de definición y construcción social. No todo acto lesivo es criminalizado, por consiguiente, se debe estudiar por qué solo unos y no otros; no toda persona que infringe una norma penal, y ni siquiera toda persona condenada, es considerada delincuente, en consecuencia, se debe investigar cuando se la etiqueta como tal y cuando no" (LARRAURI, 2015, p. 73). Sobre el tema ver AKERS y SELLERS (2009, pp. 151-176), BARATTA (1989, pp. 83-119), CID y LARRAURI (2001, pp. 199-224), HAGAN (2008, pp. 177-180), LILLY, et. al (2007, pp. $123-$ 148, NEWBURN (2013, pp. 215-232) y SERRANO (2009, pp. 437-478). A partir de esta teoría se dirige la atención a la reacción social y no solo al análisis del comportamiento delictivo CID y LARRAURI (2001, p. 220) 
compañía de Randall Adams, a quien acusó de la autoría del delito. Harris tenía varios antecedentes penales e incluso había hurtado el automóvil en el que se transportaban.

Por su parte, Randall Adams tenía 28 años de edad y se había trasladado a Dallas a buscar trabajo. El día de los hechos se transportaba con Harris, luego de hacer autostop (pedirle un aventón), consumiendo con aquel cerveza y marihuana durante el día y viendo al final del mismo una película en un auto-cinema. Adams era considerado por las autoridades un "hipster" [Con esta referencia nos aproximamos al etiquetamiento del delincuente, teoría cercana a la estigmatización de GofFMAN (1990) ${ }^{59}$, que más que ser una teoría de la criminalidad, se convierte en una teoría de la criminalización].

Puede que a estas alturas de la narrativa, el lector ya tenga un responsable y reconocemos que hemos tratado de manipular la información para que ese veredicto coincida con el objetivo de este acápite. Un etiquetamiento inicial podría apostar por la responsabilidad penal de Adams, en contravía de los mandatos del derecho penal contemporáneo que se enfoca en el acto, limitando el análisis peligrosista del autor (Roxin, 1997, Derecho penal, parte general p. 176), en el que lamentablemente se puede caer. En el presente caso la reacción social frente al crimen, etiquetó a Adams como delincuente, lo cual le significó una condena como autor responsable del delito de homicidio. Y para este efecto se unió toda la comunidad, incluso otorgando testimonios que no se compaginaban con la realidad, directamente vinculados al pago de una recompensa. 
Ahora bien, en cuanto al interés político del castigo, en el presente caso existía un ingrediente adicional: Harris era menor de edad y por ende, en su contra, no se podía aplicar la pena de muerte. Esta situación nos remonta a los criterios de prevención general analizados anteriormente, que hacían más loable -para el caso concreto-, responsabilizar a Adams para obtener ese efecto de disuasión del delito en toda la comunidad, a pesar de la existencia de un gran número de evidencias que no permitían consolidar esta decisión y eventualmente inclinarse a la determinación de responsabilidad penal en contra de Harris ${ }^{60}$.

The Thin Blue Line (1988) $)^{61}$ es útil para analizar el contraste entre las teorías positivistas, que en la conclusión del documental serían de provechosas para examinar y tratar el comportamiento de Harris, y el tránsito al análisis -desprovisto de las causas de la conducta desviada a partir del sujeto-, de la concepción generalizada de la sociedad sobre el delincuente, a partir de las formas de control.

Con base en todo esto podemos concluir que es la sociedad quien en ocasiones, termina otorgándole el rótulo de delincuente a una persona, a pesar de no tener ninguna responsabilidad penal en determinados hechos. Adicionalmente, The Thin Blue Line muestra como para Randall Adams, el sistema de justicia y sus integrantes también son outsiders (BECKER, 2009, Outsiders.

60 En similar sentido el ejemplo hipotético de McCloskey sobre la violación de una mujer blanca por un joven negro, en un pueblo del sur de los Estados Unidos. Al ser imposible individualizar al sospechoso y ante la amenaza de linchamiento en contra de varios negros, un Sheriff utilitarista inventa pruebas contra un negro cualquiera para que sea condenado y evitar así el linchamiento (NINO, 1994, p. 430)

http://www.youtube.com/watch?v=zUJfrW1hNBk 
Hacia una sociología de la desviación p. 21) y carecen de legitimidad para imponer una sanción en su contra.

\section{CRIMEN Y CONTROL SOCIAL ${ }^{62}$}

Los 400 golpes (1959) ${ }^{63}$ es una película dirigida por François Truffaut y protagonizada por Jean-Pierre Léaud (Antoine Doinel) que muestra la vida de un adolescente parisino, abandonado afectivamente por su familia y desaplicado en el colegio ${ }^{64}$. El nombre del film viene de la expresión francesa: faire les 400 coups que significa hacer todas las tonterías posibles ${ }^{65}$ pero que

62 "La persona que carece de vínculos sociales afectivos, utilitarios o normativos con instituciones sociales, como la familia, la escuela, el trabajo o el orden social, es alguien que está más predispuesto a delinquir al comportar el delito un menor coste social" (LARRAURI, 2015, p. 72). Sobre el tema ver AKers y SELLERS (2009, pp. 123-150), CID y LARRAURI (2001, pp. 177-198), GOTTFREDSON (2006, Una teoría del control explicativa del delito pp. 333-345), LILLY, et. al (2007, pp. 79-98), NEWBURN (2013, pp. 233-250) y SERRANO (2009, pp. 389-420).

63 http://www.youtube.com/watch?v=1L0smVZDBUg

64 “El joven académicamente competente posee una mayor capacidad de prever las consecuencias de sus actos y además arriesga más en el caso que decida realizar algún delito. Por el contrario, los jóvenes con poca habilidad académica pierden interés hacia la escuela y dejan de ser sensibles a lo que piensan los maestros, los cuales cesan de ser vistos como figuras dotadas de autoridad moral capaces de influir o regular su conducta" CID y LARRAURI (2001, pp. 184)

"Many expressions can't be translated literally between French and English, but the French expression faire les quatre cents coups is one that makes virtually no sense at all - you can't even guess as to what it means figuratively. I think it's partly the definite article les ("the") that makes it so difficult, as if there are 400 specific tricks that one must do in order to claim that you've lived a truly wild life.

Also, the word coup has numerous meanings; in faire les quatre cents coups, it's in the sense of un mauvais coup - "a dirty or mean trick." Unfortunately, the title of the François Truffaut's film Les Quatre Cents Coupswas poorly 
paralelamente, permite mostrar la gran cantidad de golpes que recibe Antoine Doinel en el trasegar de su infan Outsiders. Hacia una sociología de la desviación.

A propósito de la teoría del control, directamente relacionado con la anomía de Durkheim (1998) y Merton (1992), el film resulta útil para analizar la conformidad de los miembros de una sociedad frente a las normas establecidas en el contrato social y la interiorización de las mismas que los aleja de la comisión de delitos (Newburn, 2007, p. 228), proceso que debe ocurrir a temprana edad (entre los 3 y los 7 años), con el acompañamiento de ciertos grupos primarios, encabezados por la familia y la escuela (Newburn, 2007, Criminology pp. 229 y 241), quedando las sanciones penales relegadas como última medida, lo cual resulta congruente con el carácter fragmentario del derecho penal que determina que este es la ultima ratio $^{66}$.

Y es que precisamente cuando se descuida a un niño en esta etapa de formación, el proceso de interiorización de las normas se ve truncado, convirtiéndolo en un ser anómico que más adelante continuará transgrediendo las normas que son mayoritariamente aceptadas por la sociedad.

Así, el comportamiento de Antoine Doinel puede ser una clara forma de llamar la atención frente al descuido al que lo ha sometido una madre, que quedó embarazada y no pudo abortar y

translated as "The 400 Blows" in English. "400 Tricks" would have been a little better, but I think the best translation would have been something more figurative like "Raising Hell" or "The Wild One." http://french.about. com/od/vocabulary/a/faireles400coups.htm

En sentido similar, GARLAND (1999, p. 320) 
un padrastro que procura tolerarlo, pero que no le brinda amor. Por esta razón comienza con irse de la casa y su comportamiento delictivo se ve reflejado desde el apoderamiento de una botella de leche (eventualmente justificado por un estado de necesidad) hasta la sustracción de una máquina de escribir de la oficina donde trabaja su padrastro.

Aunado a lo anterior, Antoine Doinel acrecienta la pérdida de valores al observar que su principal figura de autoridad (su progenitora) trasgrede igualmente las normas socialmente aceptadas en torno a la fidelidad, cuando la sorprende besando a un sujeto que no es su padrastro. A partir de ese momento recibe aceptación por parte de aquella, no de manera sincera sino directamente interesada por el silencio que el menor debería guardar frente a su conducta.

En el caso de Antoine Doinel el internamiento en una correccional se observa como una liberación de los padres frente a una responsabilidad que le asiste a la familia como medio de control primario $^{67}$, relegando esta función al Estado (a través de un internado), sin esforzarse por brindarle cariño y atención, lo que en definitiva se traduce en un abandono que determinará la falta de asimilación de valores por parte del menor y habilitará las bases para convertirlo en Un prophète.

67 En sentido similar la muerte de Marión Le Goff, que había sido jefe de una banda célebre en Bretaña a mediados del siglo XVIII, quien gritaba desde lo alto del patíbulo: "Padres y madres que me escucháis, vigilad y enseñad bien a vuestros hijos; yo fui en mi infancia embustera y holgazana, comencé por robar un cuchillito de seis octavos... Después, robé a unos buhoneros, a unos tratantes de bueyes; finalmente fui jefe de una banda de ladrones, y por eso estoy aquí. Repetid esto a vuestros hijos y que al menos les sirva de ejemplo." (FOUCAULT, 1976, p. 70). 
Para el caso colombiano resulta paradigmático el reportaje a un niño sicario que expresa lo siguiente: "Si a mí me dedicara tiempo alguien, hasta de pronto uno cambiaría. Porque a uno nadie le dedica tiempo. Yo a mi mamá cuantas veces le dije: Ma, dedíqueme tiempo, Ma ayúdeme con las tareas Ma, vea ayúdeme" 68

\section{LA CRIMINOLOGÍA CRÍTICA Y LA LEGITIMIDAD DEL PODER DE CASTIGAR ${ }^{69}$}

La batalla de Argel (1966) ${ }^{70}$ es una película dirigida por Gillo Pontecorvo que muestra la guerra que afrontó Argelia para obtener su independencia. El argumento gira en torno a un rebelde (Alí) que inicialmente se dedicaba a estafar a los transeúntes a través de juegos de azar, razón por la cual fue detenido y llevado a prisión. Estando allí, observa la ejecución de un militante del Frente de Liberación Nacional (FNL) que combatía la opresión colonial francesa sobre Argelia, decidiendo incorporarse al mismo tras su salida de prisión, al haberse generado en él una conciencia de clase.

Similar a lo que pasa con otras películas analizadas, podríamos estudiar este film desde varias perspectivas criminológicas,

\footnotetext{
68 http://www.youtube.com/watch?v=8HU7IB6loIs

69 "La criminología critica apunta a la necesidad de estudiar cómo influye el poder de criminalización de comportamientos y en la aplicación del derecho penal y, en concreto, analiza la delincuencia y el sistema penal en el marco de la sociedad capitalista" (LARRAURI, 2015, p. 74). Sobre el tema ver AKERS y SELLERS (2009, pp. 237-266), BARATTA (1989, pp. 165-178 y 209-222), CID y LARRAURI (2001, pp. 225-252), LILLY, et. al (2007, pp. 183-206), NEWBURN (2013, pp. 251-268) y SERRANO (2009, pp. 479-503).

http://www.youtube.com/watch?v=Ca3M2feqJk8 
iniciando con el comportamiento criminal de Alí, desplegado a través de los juegos de azar, que bajo una concepción marxista (la cual será criticada más adelante) rotula al delincuente como lumpen-proletariado: un ser derrotado, perteneciente al proletariado pero improductivo y desmoralizado, que opta por el delito en vez de participar en la lucha social ${ }^{71}$. Con base en esto podríamos acuñar posturas de ecología humana y como el ambiente al cual se encuentra sometido Alí, lo lleva a continuar por un trasegar criminal durante su existencia ¿Podía optar por otro camino? Pensemos también en el libre albedrío -pregonado por la escuela clásica-, contrastado con la conciencia que generó Alí en la cárcel ${ }^{72}$ ¿Qué tanta libertad existe en su actuar? Sin embargo, y muy ligado a las teorías del etiquetamiento, es importante analizar como la detentación del poder es la que determina la calidad de delito ${ }^{73}$.

71 Este proletariado es descrito en la obra de FERRAJOLI como: "mendigos y vagabundos, individuos de ambos sexos dedicados a la prostitución y alcoholizados, fulleros y sujetos de vida equívoca, degenerados física y espiritualmente, todos ellos concurren para formar el ejército de los enemigos capitales del orden social, ejército cuyo estado mayor está formado precisamente por los delincuentes habituales" (2009, p. 269).

"Hegel eleva al delincuente a la posición de un ser libre y que se determina así mismo. Empero, si examinamos el asunto más detenidamente, descubrimos que aquí, como en casi todos los otros casos, el idealismo alemán se ha limitado a dar una sanción trascendental a las normas de la sociedad existente. ¿No es acaso un engaño sustituir al individuo con sus motivos reales y con las múltiples circunstancias sociales que influyen sobre él, por la abstracción del libre albedrio, solo una entre las muchas cualidades del hombre? Esta teoría, que considera la pena como resultado de la propia voluntad del delincuente, no es más que una expresión metafísica del viejo jus talionis: ojo por ojo, diente por diente, sangre por sangre" (MARX, 1853, citado por TAYLOR, et. al., 2007, p. 248) que escapan al control del legislador pero, como lo demuestra la aplicación de la ley sobre delincuentes juveniles, en cierto grado depende de la sociedad 
Y en este sentido es muy gráfica la película, al mostrar por una parte los bombardeos indiscriminados del ejército en procura de capturar a los insurgentes, los que contemporáneamente y especialmente luego del 9-11 estarían comprendidos bajo el nombre de "enemigos" (JAKOBS, 2009, "En los límites de la orientación jurídica: Derecho penal de enemigo" p. 31) contrastado con los actos de la FNL en los cuales, no solo se atentaba contra la fuerza pública y la institucionalidad, sino que se victimizó a los propios miembros de la sociedad civil, como daños colaterales.

Ahora bien, MARX se concentró en los problemas de la economía política y no fue exhaustivo en el estudio del delito ${ }^{74}$ y la desviación (TAYLOR, et. al., 2007 pp. 241 y 250). Muy probablemente por esto pueden erigirse varias críticas frente a sus notas marginales al respecto. Por ejemplo, si el delincuente es un ser derrotado ¿qué pasa con la delincuencia de cuello blanco ${ }^{75}$ ? (CID y LARRAURI, 2001 p. 241). MARX solo ataca la naturaleza delictiva del capitalismo como sistema (TAYLOR, et. al., 2007 p. 245) pero omite la trasgresión de la ley por personas que

oficial que determinadas violaciones de sus normas sean calificadas de delitos o simplemente transgresiones" (MARX 1859, citado por TAYLOR, et. al., 2007, p. 249)

"Marx tenía poco que decir sobre la ley penal y el control del delito. El objetivo es acá, entonces, desarrollar un análisis crítico-marxista del control del crimen en la sociedad capitalista" QUINNEY (1985, p. 243). "Ni Karl Marx ni Friedrich Engels hicieron una contribución sustantiva al análisis de las instituciones penales. En contraste con otras áreas de estudio del marxismo -Economía política, Derecho, Familia, Estado, entre otras - no existen textos básicos que presenten una posición marxista desarrollada sobre el castigo, por lo que, en consecuencia, no hay ninguna ortodoxia original que superar" GARLAND (1999, p. 106).

Sobre la delincuencia de cuello blanco ver SUTHERLAND (1940) 
ostentan un nivel socioeconómico alto. Para el caso colombiano son múltiples los escándalos relacionados con este tópico, los cuales nos remontan en la época reciente a los años 90, con los desfalcos de DRAGACOL y FONCOLPUERTOS, seguidos por las defraudaciones en CAJANAL y actualmente AIS y el escándalo de la contratación pública en Bogotá.

Por eso, ciertamente dentro de la visión neoliberal, en las controversias entre el capitalista con el trabajador, el Estado interviene siguiendo los consejos del primero (A. SMITH, 1814, citado por MARX, 2002, El Capital) ${ }^{76}$ - y en el ámbito penal, se crea una legislación de excepción donde "los propios fabricantes son los encargados de interpretar, en su función de jueces de paz” (MARX, 2002). Adicionalmente y recurriendo a BECKER a partir de una análisis marxista (TAYLOR, et. al., 2007 p. 253), son las clases dominantes quienes tienen el poder de determinación sobre las conductas delictivas, tal como se observa en la batalla de Argel, donde la fuerza pública actúa de una manera que podría calificarse de irregular desde un punto de vista externo al derecho pero que resulta legal, por el amparo del poder soberano.

En el ámbito colombiano y por fuera de un contexto bélico, piénsese en la criminalización de la minería artesanal en procura de salvaguardar la producción macroeconómica de los grandes empresarios dedicados a esta explotación.

\section{CONCLUSIONES}

Con este breve recuento cinematográfico, hemos pretendido demostrar como a través del cine, se puede abordar el estudio

76 El caso paradigmático en la actualidad sería la negociación del salario mínimo legal mensual vigente. 
de algunas categorías del derecho penal y la criminología, que pueden ser densas en el aprendizaje del derecho y en general, en la comprensión del delito como dinámica social que irradia el día a día de las personas. Con base en las películas seleccionadas se pretendió explicar algunas de las teorías criminológicas que han ocupado la atención de esta disciplina durante varios años: (i) Escuela biológica, (ii) escuela clásica y escogencia racional del crimen, (iii) escuela de Chicago y desorganización social, (iv) teoría de la asociación diferencial, (v) teoría de la anomia, (vi) teoría de las subculturas, (vii) teoría del control, (viii) teoría del etiquetamiento y (ix) criminología crítica.

También se procuró correlacionar estas representaciones foráneas, con la realidad colombiana, sustentando los planteamientos con la doctrina relacionada frente a los temas abordados. Por supuesto, el límite de hojas y el propósito de este artículo, no permitió ahondar en todas las teorías criminológicas ni mucho menos en los aspectos detallados que puede el lector encontrar en los tratados y manuales de derecho penal y criminología; sin embargo, se ofrece una aproximación para continuar con la utilización de esta herramienta pedagógica en procura de difundir el conocimiento propio de estas disciplinas, de la manera más sencilla y descriptiva posible.

El fin principal de este texto, fuertemente influenciado por el interés pedagógico del autor, consiste en brindar una alternativa de enseñanza que pueda ser replicada en el contexto colombiano y en las fronteras más cercanas, permitiendo no solo la aprehensión de conocimiento sino la construcción conjunta del mismo entre el estudiante y el docente. 


\section{BIBLIOGRAFÍA}

AGNE, ROBERT. "The Nature and Determinants of Strain: Another Look at Durkheim and Merton". En: Agnew/ Passas (eds.), The Future of Anomie Theory. Boston: Northeastern University Press, 1997, pp. 23-51.

ANDERSON, NATHANIEL y Kiehl, Kent. "The psychopath magnetized: insights from brain imaging". En: Trends in cognitive sciences, sd, 2012

AKERS, RONALD y Sellers, Christine. Criminological Theories. Introduction, evaluation and application. New York: Oxford University Press, 2009

AKERS, RONALD. Criminological theories. Los Angeles: Roxbury Publishing Company, 1994.

ATHERTON, MATHEW. "Teaching Criminology Through Film: Utilizing Popular Criminology in the Classroom". En: Journal on Excellence in College Teaching, 24(2), 2013

BARATTA, ALESSANDRO. Criminología crítica y crítica del derecho penal. México: Siglo XXI editores, 1989.

BECKER, HOWARD. Outsiders. Hacia una sociología de la desviación, Buenos Aires: Siglo XXI Editores, 2009.

CANCIO, MANUEL. Psicopatía y derecho penal: algunas consideraciones introductorias. Madrid: Oviedo, 2013. 
CID, JOSÉ y Larrauri, Elena. Teorías criminológicas. Barcelona: Bosch, 2001

Clarke, Ronald; Cornish, Derek. "Modeling Offenders. Decisions: A Framework for research and Policy". En: Tonry/Morris (eds.), Crime and justice. An Annual Review of Research, Chicago, The University of Chicago Press, 1985, pp. 147-185.

DELISI, MATT. "Revisiting Lombroso". En: Cullen/Willcox (eds.), The Oxford Handbook of Criminological Theory. New York: Oxford University Press, 2013, pp. 5-21.

DE LUCA, JAVIER. Blade Runner: el Derecho, guardián de la diferencia. Valencia: Tirant lo Blanch, 2003

DEMERATH, N.J. Through a double-crossed eye: Sociology and the movies. En: Teaching Sociology, 9(1), 1981, 69-82.

DURKHEIM, ÉMILE. La división del trabajo social. México: Colofón, 1998

FERRAJOLI, LUIGI. Derecho y razón. Teoría del garantismo penal. Traducción de Perfecto Andres Ibañez, Alfonso Ruiz Miguel,Juan Carlos Bayón Mohino, Jua Terradillos asoco, Rocío Cantarero Bandrés, Madrid: Trotta, 2009

FOUCAULT, MICHEl. Historia de la sexualidad I. La voluntad de saber. México: Siglo XXI Editores, 1991.

. La verdad y las formas jurídicas. Barcelona: Gedisa, 1998. 
- Vigilar y castigar. Nacimiento de la prisión. Traducción de Aurelio Garzón del Camino. Buenos Aires: Siglo XXI Editores, 1976.

GARCÍA - BORÉS, JOSE. "El impacto carcelario". En: Bergalli, Roberto (Coord.) Sistema penal y problemas sociales. Valencia: Tirant Lo Blanch, 2003.

GARCÍA- PABLOS DE MOLINA, ANTONIO. "Régimen abierto y ejecución penal". En: Revista Estudios Penitenciarios No. 240. Madrid, 1998

GARLAND, DAVID. "La cultura de las sociedades con altas tasas de criminalidad. Algunas precondiciones de las políticas de seguridad ciudadana". En: Crimen y castigo en la modernidad tardía, Bogotá: Siglo del Hombre, Universidad de los Andes y Pontificia Universidad Javeriana. 2007

- Castigo y sociedad moderna. Un estudio de teoría social. México: Siglo XXI editors, 1999.

. The limits of the sovereign state. En: The British Jornal of Criminology, No. 36, 1996.

. Punishment and welfare: A history of penal strategies, Aldershot: Gower, 1997.

GOFFMAN, ERVING. Stigma: Notes On The Management of Spoiled Identity. London: Penguin Group, 1990.

GOTTFREDSON, MICHAEL. "Una teoría del control explicativa del delito". En: Derecho penal y criminología como 
fundamento de la política criminal: Estudios en homenaje al profesor Alfonso Serrano Gómez. Madrid: Dykinson, 2006, pp. 333-345.

HAGAN, FRANK. Introduction to Criminology. Theories, methods and criminal behavior. Los Angeles: Sage Publications, 2008.

HERNÁNDEZ, NORBERTO. "Poder soberanoy poderdisciplinario. La codificación desde una visión foucaultiana". En: Revista de Estudios Sociales 48. Enero-Abril. Universidad de los Andes. Facultad de Ciencias Sociales, 2014.

. "Los sistemas de vigilancia electrónica como sustitutivos de la prisión desde una perspectiva analítico-económica del derecho". En: Revista Contexto. Bogotá.: Universidad Externado de Colombia, Abril de 2012, Vol. 36, 2012,pp. 79-93

JAKOBS, GÜNTHER. "En los límites de la orientación jurídica: Derecho penal de enemigo". En: Terrorismo y Estado de derecho, Bogotá: Universidad Externado de Colombia, 2009.

LANIER, MARK y Henry, Stuart. Essential Criminology. Colorado: Westview Press, 1998.

LARRAURI, ELENA. Introducción a la criminología y al sistema penal. Madrid: Trotta, 2015.

LILLY, ROBERT, Cullen, Francis y Ball, Richard. Criminological theory. Context and consequences. Los Angeles: Sage publications, 2007. 
LIVINGSTON, KATHY. "Viewing films about mental illness through a sociological lens". En: Teaching Sociology, 32(1), 2004, pp. 119-128.

MARX, KARL. El Capital, 2002, Marxists Internet Archive. Recuperado de http://www.marxists.org/espanol/

MATTHEWS, ROGER. Pagando tiempo. Una introducción a la sociología del encarcelamiento. Barcelona: Bellaterra, 2003.

MELOSSI, DARIO y Pavarini, Massimo. Cárcel y fábrica. Los orígenes del sistema penitenciario (Siglos XVI-XIX). Traducción de Xavier Massimi. México: Siglo XXI editores, 1987.

MERTON, ROBERT. Teoría y estructuras sociales, México: Fondo de Cultura Económica, 1992.

MORSE, STEPHEN. "Psycopathy and criminal responsibility". En: Neuroethics 2, 2008

NEWBURN, TIM. Criminology. Oxford: Willan Publishing, 2007. . Criminology. London y New York: Routledge, 2013.

NUÑEZ, ANTONIO. "Antecedentes y principios fundamentales del análisis económico de la ley”, En: Derecho Económico, Tomo II, Bogotá.: Universidad Externado de Colombia, 2000.

PINZÓN, MARIO.Aproximaciones al análisis económico del derecho. Bogotá.: Universidad Externado de Colombia, 2010. 
POSNER, RICHARD, Landes, William y Kelman, Mark. Análisis Económico del Derecho. Estudio preliminar de Carlos Morales de Setién Ravina, Bogotá.: Siglo del Hombre Editores, Universidad de los Andes y Pontificia Universidad Javeriana - Instituto Pensar, 2011.

POSNER, RICHARD. El análisis económico del derecho. Traducción de Eduardo L. Suarez. México D.F.: Fondo de Cultura Económica, 1998.

RAFTER, NICOLE. Shots in the mirror. Crime films and society. New York: Oxford University Press, 2006.

RAFTER, NICOLE y Brown, Michele. Criminology goes to the movies: Crime Theory and Popular culture. New York: New York Press, 2011.

ROCK, PAUL y Holdaway, Simon. "Thinking About Criminology: $<$ Facts are Bits of Biography>". En: Simon/Rock (eds.), Thinking About Criminology. London: University College London Press, 1988, pp. 1-10.

ROXIN, CLAUS. Derecho penal, parte general. Madrid: Civitas, 1997.

RUBIO, MAURICIO. Economía Jurídica. Introducción al análisis económico del derecho iberoamericano. Bogotá.: Universidad Externado de Colombia, 2007.

SERRANO, ALFONSO. Introducción a la criminología. Madrid: Dykinson, 2009. 
SuTHERLAND, EDWIN. Principios de Criminología. Chicago: University of Chicago Press, 1939. . Delincuencia de cuello blanco. New York: Holt Rinehart y Winston, 1940.

SYKES, GRESHAM. The society of captives. A study of a maximum security prison. Princeton: Princeton University Press, 1997.

TAYLOR, IAN, Walton, Paul y Young, Jock. La nueva criminología. Contribución a una teoría social de la conducta desviada. Buenos Aires: Amorrotu editores, 2007.

URBANO, JOSÉ. La legitimidad de derecho penal. Equilibrio entre fines, funciones y consecuencias. Bogotá, Universidad Externado de Colombia, 2001.

VON HIRSCH, Andrew, Bottoms, Anthony E., Burney. Elizabeth y Wikstrom, P-O. Criminal deterrence and sentence severity. Oxford: Hart Publishing, 1999.

WILSON, JAMES. Thinking about crime. New York: Vintage, 1975.

YOUNG, JOCK. La sociedad excluyente: exclusión social, delito y diferencia en la modernidad tardía. Madrid: Marcial Pons, 2003. 